\section{OP0016 COMPARATIVE EFFECTIVENESS AT 1 YEAR OF DIFFERENT ANTI-TNF DRUGS AS FIRST BIOLOGIC DMARD IN PATIENTS WITH RHEUMATOID ARTHRITIS - RESULTS FROM THE NATIONWIDE SWEDISH REGISTER}

C. Turesson ${ }^{1,2}$, T. Frisell ${ }^{3}$, M. Dehlin ${ }^{4}$, D. Di Giuseppe ${ }^{3}$, N. Feltelius ${ }^{5}$, A. Kastbom ${ }^{6}$, J. Askling ${ }^{3}$ on behalf of ARTIS study group. ${ }^{1}$ Department of Rheumatology, Skåne University Hospital; ${ }^{2}$ Rheumatology, Department of Clinical Sciences, Malmö, Lund University, Malmö; ${ }^{3}$ Department of Medicine, Karolinska Institutet, Stockholm; ${ }^{4}$ Department of Rheumatology and Inflammation Research, Sahlgrenska Academy, Gothenburg University, Gothenburg; ${ }^{5}$ Medical Products Agency, Uppsala; ${ }^{6}$ Rheumatology/AIR, Department of Clinical and Experimental Medicine, Linköping University, Linköping, Sweden

Background: Treatment with TNF inhibitors is part of the management of patients with severe rheumatoid arthritis (RA). There is limited data on the comparative effectiveness of different TNF inhibitors from clinical trials and observational studies of patients treated in clinical practice.

Objectives: To compare effectiveness of different TNF inhibitors in a large, population representative, sample of bionaïve patients with RA.

Methods: The study was based on the Swedish Rheumatology Quality register, in which clinical data are prospectively recorded at treatment initiation and at subsequent visits. Patients with RA initiating a TNF inhibitor as their first ever biologic DMARD in 2010-2014 were included and followed through 2015. The proportion remaining on drug at 1 year ( \pm 90 days) after starting therapy was compared. Furthermore, effectiveness at 1 year was assessed as the proportions with EULAR good response, remission (DAS28 <2.6), HAQ improvement $(>0.2)$ and swollen and tender joint counts of 0 , all corrected for drug survival (1). The relative response was estimated with log-binomial regression, adjusting for potential confounders and using the largest group (etanercept) as reference.

Results: A total of 5568 patients were included. There was a significant difference in the adjusted chance of drug survival across TNF inhibitors (Table). Patients treated with certolizumab or infliximab were less likely to remain on treatment compared to those started on etanercept. The chance of achieving each of the clinical response measures was significantly lower for those initiating infliximab compared to patients treated with etanercept. There were no significant differences in these outcomes compared to etanercept for any of the other TNF inhibitors.

Conclusions: Patients with RA starting infliximab as their first biologic DMARD were less likely to remain on treatment with significant improvement at 1 year compared to those initiating etanercept. There was a similar trend for certolizumab vs. etanercept, but there were no consistent differences in clinical effectiveness between etanercept and adalimumab or golimumab. Treatment context may affect these patterns.

\section{References:}

[1] Kristensen A\&R 2006; 54: 600-6.

Disclosure of Interest: C. Turesson Grant/research support from: Abbvie, Pfizer, Roche, Consultant for: MSD, Pfizer, Roche, Paid instructor for: Abbvie, BristolMyers Squibb, Janssen, MSD, Pfizer, Roche and UCB, T. Frisell: None declared, M. Dehlin: None declared, D. Di Giuseppe: None declared, N. Feltelius: None declared, A. Kastbom Consultant for: Bristol-Myers Squibb, Pfizer, Roche, UCB, Paid instructor for: Bristol-Myers Squibb, Pfizer, Roche, UCB, J. Askling Grant/research support from: Abbvie, UCB, Pfizer, Merck, Samsung, Roche, Lilly DOI: 10.1136/annrheumdis-2017-eular.2760

\section{OP0017 LACK OF PLACENTAL TRANSFER OF CERTOLIZUMAB PEGOL DURING PREGNANCY: RESULTS FROM CRIB, A PROSPECTIVE, POSTMARKETING, MULTICENTER, PHARMACOKINETIC STUDY}

X. Mariette ${ }^{1}$, A. Flynn ${ }^{2}$, F. Förger ${ }^{3}$, A. Moltó ${ }^{4}$, R.-M. Flipo ${ }^{5}$, A. van Tubergen ${ }^{6}$, L. Shaughnessy ${ }^{7}$, J. Simpson ${ }^{7}$, M. Teil ${ }^{8}$, E. Helmer ${ }^{9}$, M. Wang ${ }^{7}$,

E. Chakravarty ${ }^{10} .{ }^{1}$ Université Paris-Sud, le Kremlin-Bicêtre, France; ${ }^{2}$ University of Utah, Salt Lake City, United States; ${ }^{3}$ Inselspital, University of Bern, Bern, Switzerland; ${ }^{4}$ Groupe Hospitalier Cochin, AP-HP, Paris, ${ }^{5}$ Centre Hospitalier
Régional Universitaire de Lille, Lille, France; ${ }^{6}$ Maastricht University Medical Center, Maastricht, Netherlands; ${ }^{7}$ UCB Pharma, Raleigh, United States; ${ }^{8}$ UCB Pharma, Slough, United Kingdom; ${ }^{9}$ UCB Pharma, Brussels, Belgium;

${ }^{10}$ Oklahoma Medical Research Foundation, Oklahoma City, United States

Background: There is a need for effective and safe treatment during pregnancy in women affected by chronic active inflammatory diseases, such as rheumatoid arthritis. Adequate disease control is crucial to ensure the best fetal and maternal health, and reduce adverse pregnancy outcomes..$^{1,2}$ Anti-TNFs are an effective therapeutic option, but because most cross the placenta, they are often stopped during pregnancy. ${ }^{3,4}$ Certolizumab pegol (CZP), due to its Fc-free molecular structure, has no active placental transfer compared to other anti-TNFs. 5,6

Objectives: To accurately measure the potential level of placental transfer of CZP from mothers to infants using a highly sensitive, CZP-specific assay.

Methods: CRIB (NCT02019602) was a pharmacokinetic (PK) study of pregnant women ( $\geq 30$ weeks [wks] gestation) receiving commercial CZP (maintenance dose) for an approved indication; last dose was within 35 days prior to delivery. Blood samples were collected from the mothers, umbilical cords, and infants at delivery, and infants again at Wks 4 and 8 post-delivery. CZP concentration was measured with a sensitive, CZP-specific electrochemiluminescence immunoassay validated in plasma ( $L L O Q=0.032 \mu \mathrm{g} / \mathrm{mL}$; 10 -fold lower than assay used in prior CZP PK studies ${ }^{6,7}$ ).

Results: 21 CZP-treated pregnant women were screened; 16 entered the study (Table). Maternal CZP plasma levels at delivery were within the expected therapeutic range (median [range]: $24.4[5.0-49.4] \mu \mathrm{g} / \mathrm{mL}$ ). Of the 16 infants delivered, 2 samples were excluded: 1 due to missing data, 1 due to implausible PK data. 13/14 infants had no quantifiable CZP levels at birth $(<0.032 \mu \mathrm{g} / \mathrm{mL})$; 1 infant had a minimal CZP level of $0.042 \mu \mathrm{g} / \mathrm{mL}$ (infant/mother plasma ratio: $0.09 \%$ ); no infants had quantifiable levels at Wks 4 and 8 (Figure). $3 / 15$ umbilical cord samples had quantifiable CZP levels (maximum: $0.048 \mu \mathrm{g} / \mathrm{mL}$ ); 1 umbilical cord collapsed and was excluded. No anti-CZP antibodies were detected in mothers, umbilical cords, or infants. The infants of CZP-exposed mothers had a safety profile consistent with that of unexposed similar-age infants.

Table: Baseline characteristics of mothers and infants

\begin{tabular}{lc}
\hline Median (min, max), unless stated otherwise & All mothers $(\mathrm{n}=16)[\mathrm{a}]$ \\
\hline Age, years & $31(18,40)$ \\
Mother's indication for CZP treatment, $\mathrm{n}$ & \\
Rheumatoid arthritis & 11 \\
Crohn's disease & 3 \\
$\quad$ Psoriatic arthritis & 1 \\
$\quad$ Axial spondyloarthritis/ankylosing spondylitis & 1 \\
\hline Median (min, max), unless stated otherwise & All infants $(\mathrm{n}=16)$ \\
\hline Female, $\mathrm{n}(\%)$ & $10(62.5)$ \\
Gestational age at birth, weeks & $39.9(37.7,41.7)$ \\
Weight at birth, $\mathrm{kg}$ & $3.3(2.6,4.0)$ \\
\hline
\end{tabular}

Figure: Plasma CZP concentrations in mothers and infants ( $n=14$ mother-infant pairs $[b])$

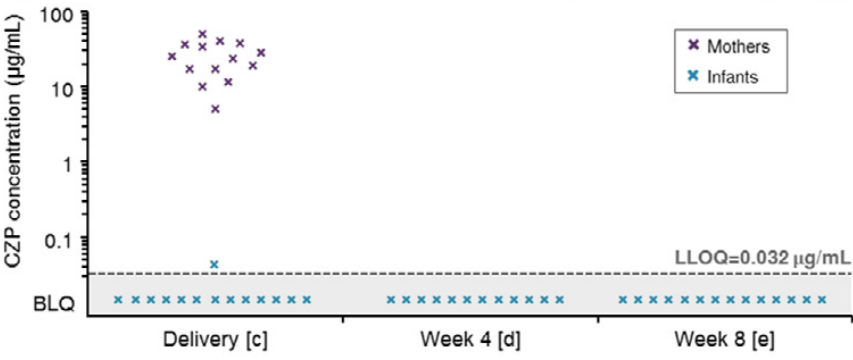

a] Mothers who entered the study: [b] 2/16 infant samples were excluded: 1 due to missing data and 1 due to implausibe PK data (ie. data notconsistent with a paediatric CZP PK model, based on the expected range of clearance, volume of distribution, and subsequent elimination half-life); [c] \pm 24 hours; [d] \pm 7 days ( 2 samples not collected): $[e] \pm 7$ days. Min: minimum; Max: maximum; BLQ: below the LLOQ $(<0.032 \mu \mathrm{g} / \mathrm{mL})$; LLOQ: lower limit of quantitation

Conclusions: Using a highly sensitive assay, CZP levels were below LLOQ in 13/14 infant blood samples at birth, and all samples at Wks 4 and 8 . This indicates no to negligible placental transfer of CZP from mothers to infants, suggesting lack

Abstract OP0016 - Table 1. Status at the 1-year evaluation visit among patients with RA initiating a TNF inhibitor as their first ever biologic DMARD

\begin{tabular}{|c|c|c|c|c|c|c|}
\hline & $\begin{array}{c}\text { Etanercept } \\
N=1651\end{array}$ & $\begin{array}{c}\text { Infliximab } \\
N-1366\end{array}$ & $\begin{array}{c}\text { Adalimumab } \\
N=1004\end{array}$ & $\begin{array}{c}\text { Certolizumab } \\
N-921\end{array}$ & $\begin{array}{c}\text { Golimumab } \\
N=626\end{array}$ & $P$ \\
\hline \multicolumn{7}{|l|}{ Observed percentage } \\
\hline On drug & 70.6 & 66.4 & 69.2 & 65.2 & 68.0 & \\
\hline EULAR good response* & 28.0 & 23.9 & 25.9 & 24.3 & 27.8 & \\
\hline DAS28 remission* & 25.9 & 21.3 & 26.0 & 22.4 & 27.7 & \\
\hline $\mathrm{HAQ}$ improvement ${ }^{\star}$ & 28.0 & 24.5 & 29.0 & 25.0 & 24.8 & \\
\hline 28 Joint counts $=0^{*}$ & 23.3 & 16.8 & 20.4 & 19.0 & 21.6 & \\
\hline \multicolumn{7}{|c|}{ Adjusted $^{\dagger}$ relative risk $(95 \% \mathrm{Cl})$} \\
\hline On drug & Ref. & $0.94(0.89-1.00)$ & $0.98(0.92-1.04)$ & $0.90(0.84-0.96)$ & $0.97(0.90-1.04)$ & 0.02 \\
\hline EULAR good response ${ }^{\star}$ & Ref. & $0.82(0.70-0.96)$ & $0.95(0.80-1.12)$ & $0.84(0.70-1.01)$ & $0.96(0.79-1.17)$ & 0.10 \\
\hline DAS28 remission* & Ref. & $0.83(0.70-0.98)$ & $1.02(0.85-1.21)$ & $0.89(0.74-1.08)$ & $1.00(0.82-1.23)$ & 0.12 \\
\hline HAQ Improvement* & Ref. & $0.82(0.70-0.96)$ & $1.04(0.89-1.21)$ & $0.86(0.73-1.03)$ & $0.86(0.71-1.05)$ & 0.02 \\
\hline 28 Joint count $=0^{*}$ & Ref. & $0.74(0.61-0.89)$ & $0.91(0.75-1.11)$ & $0.85(0.69-1.04)$ & $0.91(0.73-1.13)$ & 0.03 \\
\hline
\end{tabular}

${ }^{*}$ LUNDEX corrected (1). ${ }^{\dagger}$ Sex, age, disease duration, RF, co-treatment (methotrexate, glucocorticoids.) 
of in utero fetus exposure during the second and third trimesters. These results support continuation of CZP treatment during pregnancy.

\section{References:}

[1] de Man Y. Arthritis Rheum 2009;60:3196-206.

[2] Morales M. Hepatogastroenterology 2000;47:1595-8.

[3] Ng S. Expert Rev Clin Immunol 2013;9:161-73.

[4] Østensen M. Curr Opin Pharmacol 2013;13:470-5.

[5] Porter C. J Reprod Immunol 2016;116:7-12.

[6] Mahadevan U. Clin Gastroenterol Hepatol 2013;11:286-92.

[7] Lacroix B. Gastroenterol 2010;138:S163-4.

Acknowledgements: This study was funded by UCB Pharma. We are indebted to the mothers and their infants for their altruistic participation. Editorial services were provided by Costello Medical Consulting.

Disclosure of Interest: X. Mariette Grant/research support from: Biogen, Pfizer, UCB Pharma, Consultant for: Bristol-Myers Squibb, GlaxoSmithKline, LFB, Pfizer, UCB Pharma, A. Flynn Grant/research support from: UCB Pharma, F. Förger Grant/research support from: UCB Pharma, Speakers bureau: Mepha, Roche, UCB Pharma, A. Moltó Grant/research support from: MSD, AbbVie, Pfizer, UCB Pharma, Consultant for: MSD, AbbVie, Pfizer, UCB Pharma, R.-M. Flipo Consultant for: UCB Pharma, A. van Tubergen Grant/research support from: Pfizer, AbbVie, UCB Pharma, Janssen-Cilag, Celgene, Novartis, MSD, Consultant for: AbbVie, Novartis, Janssen-Cilag, Pfizer, Speakers bureau: MSD, JanssenCilag, Pfizer, L. Shaughnessy Employee of: UCB Pharma, J. Simpson Employee of: UCB Pharma, M. Teil Employee of: UCB Pharma, E. Helmer Employee of: UCB Pharma, M. Wang Employee of: UCB Pharma, E. Chakravarty Grant/research support from: UCB Pharma

DOI: 10.1136/annrheumdis-2017-eular.1640

\section{OP0018 TOOL AND THRESHOLD PREDICTING A SUCCESSFUL BIOLOGICAL DMARDS TAPERING IN PATIENTS WITH RA REMISSION DETERMINATION}

C. Barral ${ }^{1}$, D. Hajage ${ }^{2}$, B. Fautrel ${ }^{2}$, P. Lafforgue ${ }^{3}$, F. Tubach ${ }^{2}$, T. Pham $^{3} .{ }^{1}$ Aix Marseille University, APHM, Marseille; ${ }^{2}$ Univ. Paris Diderot, Sorbonne, APHP, Paris; ${ }^{3}$ Aix Marseille University, APHM, Marseille, France

Background: Tapering trials confirmed the feasibility of TNF inhibitors (TNFi) tapering for a relevant proportion of patients in remission and/or low disease activity. However, there are no consensual predictors of a good response to therapeutic spacing among patients with rheumatoid arthritis (RA) in remission.

Objectives: To determine the most predictive tool and threshold of a successful TNFi tapering.

Methods: Population: The Spacing of TNF-blocker injections in Rheumatoid Arthritis Study (STRASS) trial included 137 RA patients fulfilled the ACR 1987 criteria with sustained (at least 6 months) DAS28 <2.6. Patients were randomly assigned to one of the two following strategies: in the Maintain arm, patients continued to receive TNFi at the standard full regimen and in the Spacing arm, the strategy applied progressive spacing of ADA or ETN subcutaneous injections up to discontinuation at the forth step in the spacing arm. We used the data of the Spacing arm.

Analysis: The performances of several variables (DAS28, SDAI, CDAI, CRP, ACPA status, HAQ, patient/physician global assessment, and booleen remission criteria) were assessed for the prediction of successful TNFi tapering, defined as reaching at least $25 \%$ tapering of the full regimen during at least 6 months, using sensitivity and specificity for dichotomous variables, or the area under the ROC curve (AUC) and its 95\% confidence interval for continuous variables. A predictive score of successful tapering was constructed using LASSO regression modeling technique to avoid overfitting ( $R$ software version 3.2.1).

Results: The main characteristic of the 64 patients of the Spacing arm were the following (mean $\pm S D$ ): age $54.3 \pm 10.7$ years, disease duration $8.3 \pm 5.4$ years, and DAS $281.9+0.6$.

The baseline variables were similar between patients who failed or succeeded at TNFi spacing, except for the HAQ score $(0.30$ in the group success and 0.89 in the failure group, $\mathrm{p}=0.01)$ and the CRP $(2.35 \mathrm{mg} / \mathrm{l}$ versus $3.48 \mathrm{mg} / \mathrm{l}$, respectively, $\mathrm{p}=0.02$ ).

Baseline variables performance in predicting successful TNFi spacing: None of the tested variables was able to predict successful TNFi spacing, except the HAQ score and the CRP. A HAQ threshold $\geq 1.125$ had a specificity (Spe) of $93 \%$ and an AUC: 0.713 (CI95\%: 0.540-0.886). A CRP threshold $\geq 6.8 \mathrm{mg} / \mathrm{l}$ had a Spe of 0.97 and an AUC: 0.689 (CI95\%: 0.547-0.831).

Composite criteria: A composite criteria able to predict successful TNFi spacing has been elaborated, including ACPA status, Boolean criteria, SDAI, CRP and HAQ. A composite score lower than 0.502 was able to predict a successful TNFi spacing: Spe: 100\%; Se: 54\%; AUC: 0.829 (C195\%: 0.671 - 0.986).

Conclusions: The remission maintenance in rheumatoid arthritis after TNFi spacing is possible. Our results showed that in a population of RA patients in remission with TNFi, baseline HAQ and CRP are independent predictor factors of successful tapering. We have developed a composite index able to predict successful TNFi spacing, with an AUC of 0.829 and a specificity of $100 \%$. A validation study will be needed to confirm its ability to select patients for treatment decrease.

Disclosure of Interest: None declared

DOI: 10.1136/annrheumdis-2017-eular.5786

\section{OP0019 DMARD WITHDRAWAL IN RA PATIENTS ACHIEVING THERAPEUTIC RESPONSE WITH CERTOLIZUMAB PEGOL COMBINED WITH DMARDS: INTERIM RESULTS FROM A CANADIAN OBSERVATIONAL RANDOMIZED STUDY}

J. Pope ${ }^{1}$, E. Rampakakis ${ }^{2}$, E. Grant ${ }^{3}$, L. Bessette ${ }^{4}$, J. Lazovskis ${ }^{5}$, B. Haraoui ${ }^{6}$ J.S. Sampalis ${ }^{2,7} .{ }^{1}$ Medicine, University of Western Ontario, London; ${ }^{2}$ JSS Medical Research, St-Laurent; ${ }^{3}$ Private Practice, Saint John; ${ }^{4}$ Medicine, Laval University, Quebec; ${ }^{5}$ Riverside Professional Centre, Sydney; ${ }^{6}$ Institut de Rhumatologie de Montréal; ${ }^{7}$ McGill University, Montreal, Canada

Background: The efficacy and safety of certolizumab pegol in the treatment of adult patients with moderate to severe rheumatoid arthritis (RA), when administered either in combination with methotrexate (MTX) or as monotherapy, has been previously shown in several controlled clinical trials. However, a detailed assessment of certolizumab pegol in combination with a wide range of non-biologic disease-modifying drugs (nbDMARDs) used in real-life routine clinical practice is lacking compared to switching to monotherapy after achieving a response when added to $\mathrm{nbDMARD}(\mathrm{s})$.

Objectives: The objective is to compare the effectiveness and tolerability of certolizumab pegol given as add-on to nbDMARDs, including MTX and others, or as monotherapy after achieving a DAS28(ESR) improvement of $>1.2$ In this descriptive interim analysis, preliminary data on the effectiveness of certolizumab pegol given in combination nbDMARDs or monotherapy, are presented.

Methods: RA patients who had certolizumab pegol added to their existing DMARD regimen due to inadequate response to their $n b D M A R D(s)$ were eligible. At 3 or 6 months, those patients who achieved a change in DAS28 of $\geq 1.2$ were randomized to continue combination therapy (Combination group) or withdraw nbDMARD therapy (Monotherapy group) and be followed for 18 months. A sample size of 125 randomized patients per group was calculated to have 100 randomized (50 per group) to find a difference of $15 \%$ in response.

Results: A total of 121 patients were enrolled, of whom 79 were randomized to continue combination therapy $(n=35)$ or withdraw nbDMARDs $(n=44)$. No significant differences were observed between-groups in baseline age, gender ( $83 \%$ vs. $71 \%$ female), race $(89 \%$ vs. $91 \%$ Caucasian), rheumatoid factor status ( $56 \%$ vs. $60 \%$ positive), or prior biologic experience (17\% vs. $11 \%$ ).

At 18 months, upon adjusting for baseline scores, similar improvements were observed between groups in DAS28 ESR (-2.1 vs. -2.0). Furthermore, the odds of achieving DAS28 LDA (OR [95\% Cl]: 0.96 [0.28-3.31]), $\triangle \mathrm{DAS} 28>1.2$ (0.97 [0.29-3.26]), or both (1.00 [0.29-1.49]), were not different between the Combination and Monotherapy groups. Similarly, no differences were observed between groups at 12 months of treatment with respect to these outcomes.

Conclusions: The results of this interim analysis suggest that, among RA patients achieving a therapeutic response when on combination therapy with certolizumab pegol and nbDMARDs, nbDMARDs could be withdrawn without impact on treatment effectiveness over the next year. Additional analyses with the full number of patients will be conducted to confirm this finding.

Disclosure of Interest: None declared

DOI: 10.1136/annrheumdis-2017-eular.6654

\section{OP0020 ASSESSMENT OF 3-MONTH CHANGES IN BONE MICROSTRUCTURE UNDER ANTI-TNF $\alpha$ THERAPY IN PATIENTS WITH RHEUMATOID ARTHRITIS USING HR-PQCT}

T. Shimizu ${ }^{1}$, H.J. Choi ${ }^{1}$, U. Heilmeier ${ }^{1}$, M. Tanaka ${ }^{1}$, A.J. Burghardt ${ }^{1}$, J. Gong ${ }^{1}$, N. Chanchek ${ }^{1}$, T.M. Link ${ }^{1}$, J. Graf ${ }^{2}$, J.B. Imboden ${ }^{2}$, X. Li ${ }^{1} .{ }^{1}$ Department of Radiology \& Biomedical Imaging, Musculoskeletal Quantitative Imaging Research; ${ }^{2}$ Department of Medicine, Division of Rheumatology, University of California San Francisco, San Francisco, United States

Background: Bone erosions are usually thought to be irreversible and occur in the first few months of RA onset. With its resolution of up to $81 \mu \mathrm{m}$, HR-pQCT has emerged as valuable tool to assess bone changes in $\mathrm{RA}^{(1,2)}$. Although one previous study showed minimal erosive progression in patients with RA one year after TNF $\alpha$ inhibition therapy ${ }^{(3)}$, no studies have investigated yet the very early bone changes after the initiation of anti-TNF $\alpha$ treatment.

Objectives: To investigate the early changes in bone erosion progression and bone microarchitecture in the MCP joints and wrist of RA patients using HR-pQCT, radiographs, and $3 T$ MRI after 3 months of anti-TNF $\alpha$ treatment.

Methods: 26 RA patients underwent 3T MRI wrist scans and HR-pQCT scans of the MCP and wrist joints at baseline (BL) and at 3 months (3M). Radiographs were obtained at the baseline time point only. DAS28 was assessed at BL and 3M. Patients were divided into two groups: the anti-TNF $\alpha$ group and the MTX-only group.HR-pQCT-derived erosion volume, joint volume/width and bone microarchitectural parameters were computed using methods previously developed ${ }^{(4-6)}$, and the joint destruction was assessed via Sharp and RAMRIS scorings using radiographs and MR images respectively.

Results: Patients in the Anti-TNF $\alpha$ group were slightly younger than patients in the MTX only group and had a higher initial DAS28 score,but otherwise displayed similar anthropometerics and demographics (Table).

DAS scores significantly improved in the anti-TNF $\alpha$ group from BL to $3 \mathrm{M}$ (Fig. A). 75 erosions were identified at BL by HR-pQCT. The anti-TNF $\alpha$ group showed a significant decrease of erosion volume from $\mathrm{BL}$ to $3 \mathrm{M}$ at $\mathrm{MCH} 3$ (with decreasing trend at $\mathrm{MCH} 2$ and wrist). The MTX-only group in contrast, displayed significant 